\title{
The (in)stability of voters' perceptions of competence and associative issue ownership: The role of media campaign coverage
}

\author{
Prof. Dr. Anke Tresch* \\ FORS and Institute of Political, Historical and International Studies (IEPHI) \\ University of Lausanne \\ Unil-Mouline, Géopolis, Room 5628 \\ 1015 Lausanne, Switzerland \\ ankedaniela.tresch@unil.ch \\ ORCID: 0000-0003-1762-1965 \\ Alexandra Feddersen \\ Department of Political Science and International Relations \\ University of Geneva \\ Bd du Pont-d'Arve 4 \\ 1211 Geneva 4, Switzerland \\ alexandra.feddersen@unige.ch \\ ORCID: 0000-0003-1669-5292
}

*Corresponding author

Funding details:

This work was supported by the Swiss National Science Foundation under Grant number 100017-165489.

This is a post-peer-review, pre-copy-edited version of the following article:

Anke Tresch \& Alexandra Feddersen (2018). The (in)stability of voters' perceptions of competence and associate issue ownership: The role of media coverage. Political Communication, doi: https://doi.org/10.1080/10584609.2018.1542416. Supplemental and replication material can be found here: goo.gl/Z5QCm5. 


\title{
The (in)stability of voters' perceptions of competence and associative issue ownership: The role of media campaign coverage ${ }^{1}$
}

\begin{abstract}
Recent work has suggested that issue ownership has a competence and an associative dimension and that both dimensions are less stable than originally assumed. This study is the first attempt to directly compare the stability and change of voters' perceptions on both dimensions. Using data from the 2015 Swiss Election Study, linking data from a combined panel/rolling cross-section survey with an extensive media analysis, this study finds that voters are more likely to maintain their issue ownership perceptions if the party they identify as the issue owner before the campaign receives a higher share of media campaign coverage. This stabilizing effect is conditional on the importance of the issue for the voter, and it is stronger for voters' competence evaluations than for their party-issue associations, which proved to be more stable. Thus, the results confirm the literature's previously untested assumption that voters' associative ownership perceptions are more stable than their competence ownership evaluations.
\end{abstract}

\section{Introduction}

Since the trailblazing studies by Budge and Farlie (1983a, 1983b) and Petrocik (1996), numerous studies have demonstrated the role of issue ownership as a determinant of both party competition (e.g., Damore, 2004; Dolezal et al., 2014; Sides, 2006) and electoral behavior (e.g., Bélanger and Meguid, 2008; Green and Hobolt, 2008; Lachat,

\footnotetext{
${ }^{1} \mathrm{We}$ would like to thank the three reviewers and the editor for their insightful comments and suggestions. Previous versions of this article have been presented at the Annual Conference of the Swiss Political Science Association in 2016, the Dreiländertagung in Heidelberg in 2016, and the Midwest Political Science Association in 2017, as well as in research seminars at the Universities of Lausanne, Vienna, and Antwerp, where we received valuable input from various participants.
} 
2014; van der Brug, 2004). Simply put, issue ownership refers to the fact that parties are, in the minds of voters, associated with specific issues and considered as most competent to deal with them (Budge and Farlie, 1983a, 1983b; Petrocik, 1996). For parties, holding ownership of an issue can be a crucial electoral asset because voters tend to cast their ballot for the party that owns an issue of importance to them. Therefore, to win votes, parties have incentives to focus their campaign efforts on owned issues and to sidestep or downplay issues that play in favor of their competitors. While issue ownership has long been used as a stable independent variable in the party and voting behavior literatures, scholars have recently started to investigate issue ownership as a phenomenon in its own right, leading to important new insights. It is now largely acknowledged that issue ownership has two analytically distinct dimensions: competence issue ownership, which refers to a party's perceived issuehandling capacity and its ability to resolve problems of concern to voters, and associative issue ownership, which relates to a party's reputation of caring for and being committed to specific issues (e.g., Walgrave et al., 2012). Furthermore, new studies have provided evidence of the dynamic character of parties' issue ownership. While voters' issue ownership perceptions appear relatively stable and persistent on the aggregate level (Seeberg, 2017), albeit not completely resistant to change (e.g., Bélanger, 2003; Christensen et al., 2015), individual voters' issue ownership assessments appear to be highly variable and dynamic (Kleinnijenhuis and Walter, 2014; Lanz and Sciarini, 2016). Although both dimensions of issue ownership have been shown to fluctuate on the individual level in response to campaign information in the media or from parties (e.g., Aalberg and Jenssen, 2007; Dahlberg and Martinsson, 2015; Tresch et al., 2015; Walgrave and Lefevere, 2017; Walgrave et al., 2014; Walgrave et al., 2009; Walgrave and de Swert, 2007), it is often argued that the associative dimension is more stable than competence issue ownership evaluations 
(e.g., Tresch et al., 2015). However, previous work has never directly compared the (in)stability of both dimensions of issue ownership in a single study.

We set out to fill this void by comparing, for the first time, the (in)stability of individual perceptions of parties' associative and competence issue ownership during election campaigns. By assessing the validity of the untested assumption in the literature that associative issue ownership is more stable than competence issue ownership, this study will advance our understanding of the origins and dynamics of both issue ownership dimensions. In contrast to previous works on issue ownership stability and change that are mostly based on experimental designs (e.g., Dahlberg and Martinsson, 2015; Tresch et al., 2015; Walgrave et al., 2014; Walgrave et al., 2009), we use a unique dataset from a combined online panel/rolling cross-section survey from the 2015 Swiss National Election Study (Selects, 2016). Although experiments are strong instruments to detect causal links, it is unclear to what extent they can generate insights into real-world campaign dynamics. We combine this survey data with data from an extensive, automated media content analysis to test the assumption that perceptions of associative issue ownership are more stable and less influenced by media coverage than competence ownership evaluations. This comparison has not only the potential to advance our understanding of the sources of the two issue ownership dimensions and the differences between them but also to inform us about the role of the press in democratic elections.

Our empirical analysis is divided into two parts. First, we compare the stability of individual voters' perceptions of competence and associative issue ownership during the 2015 Swiss national election campaign. Second, we analyze the stability of voters' issue ownership perceptions in a multivariate framework by paying special attention to the role of media coverage. We find a significant impact of media coverage on voters' likelihood to maintain their issue ownership perceptions. However, this 
stabilizing effect holds only for issues of importance to voters, and it is stronger for their evaluation of competence ownership than for perceptions of associative issue ownership. Voters' assessments of competence issue ownership are more volatile, meaning that parties can more easily lose their competence reputation. However, for salient issues, they also have the chance to defend this reputation by being present in issue-specific media campaign coverage. These results underscore the importance of the conceptual distinction between associative and competence issue ownership. In addition, the results suggest that the media can play an important role in elections: by covering parties and issues, they affect voters' understanding of party competence and commitment toward these issues.

We proceed as follows. Based on a short literature review, we derive our expectations about the differential impact of media coverage on a voter's assessment of competence and associative issue ownership. We then present our data, measures, and model before turning to descriptive and multivariate analyses to test our hypotheses. We conclude with a discussion of the implications for studies of party competition and electoral behavior and with directions for future research.

The two faces of issue ownership: stable associations, variable competence attributions?

It is now widely acknowledged that issue ownership is a multidimensional phenomenon, with a competence and an associative dimension (Walgrave et al., 2015). Competence issue ownership refers to a party's issue-handling capacity and ability to resolve problems of concern to voters (Petrocik, 1996: 826). From this perspective, issue-owning parties are able to develop “effective policy-making” (Sides, 2006: 411), to "deliver policies" (Bellucci, 2006: 551), and to "better achieve the outcomes they promise to the public" (Egan, 2008: 9). Some authors also conceive competence issue 
ownership in positional terms, focusing on the alleged superiority of parties' policy solutions. For instance, Petrocik et al. (2003: 601) see issue ownership as a major asset for parties because it is an indicator of an ability to "implement superior policies and programs" (emphasis added) on party-owned issues. Similarly, Budge and Farlie (1983a: 282) also noted that some issues "belong" to a party because it is "generally regarded as most likely to do what is best on it" (emphasis added). In line with this conceptualization, scholars often use measurements of competence issue ownership that assess voters' beliefs about which party offers the "best policies" (Green and Hobolt, 2008; Walgrave et al., 2009) or the "best solutions" for different issues (Lachat, 2014).

Whereas competence issue ownership has an evaluative component, associative issue ownership relates to a spontaneous identification between some parties and issues, regardless of whether a voter agrees with a party or considers it to be competent (Walgrave et al., 2012; Kleinnijenhuis and Walter, 2014). This spontaneous identification arises from a "history of attention, initiative, and innovation" (Petrocik, 1996: 826) toward issues that are linked to the interests of traditional party constituencies and rooted in deep social cleavages. Therefore, associative issue ownership is a reputation for having clear issue "priorities" (e.g., Bellucci, 2006: 550; van der Brug, 2004: 211) and for being particularly "dedicated" (e.g., Aalberg and Jenssen, 2007: 119; Stubager and Slothuus, 2013: 568) and "committed" (Petrocik, 1996: 826) to dealing with an issue.

This conceptual distinction also has empirical value. The two dimensions of issue ownership are correlated but not identical. For instance, voters in many Western European countries associate the issue of migration and asylum with right-wing (populist) parties; however, few individuals consider these parties the most competent at handling the issue (e.g., Lutz and Sciarini, 2016, for evidence on Switzerland). On 
the individual level, the correlation between the two dimensions is even fairly negligible (Walgrave et al., 2012). ${ }^{2}$

Both dimensions are implicitly present in the early formulations of the issue ownership theory by Budge and Farlie (1983) and Petrocik (1996). Referring to the sources of issue ownership, Petrocik (1996: 827) distinguished between "performance-based" and "constituency-based" issue ownership. The latter is akin to the associative dimension, whereas the former resembles the competence dimension of issue ownership. His empirical analysis, as well as most of the subsequent work in the field, is based on a measurement that only taps into the competence dimension of issue ownership. ${ }^{3}$ Although Petrocik (1996: 826) generally sees voters' issue ownership perceptions as "critical constants" between elections, he admits they are not completely frozen. His writings suggest that associative issue ownership is a rather stable party characteristic, whereas competence issue ownership is more variable. Given that competence issue ownership stems from a party's "good performance" on an issue (Budge and Farlie, 1983b: 24-5), it can be lost in the short-term when the incumbent party can be blamed for bad times (e.g., wars, economic recession, increasing crime rates; Petrocik, 1996: 827). On most other issues, parties are expected to have a firm and long-term advantage over their competitors, and this advantage developed over a long time based on the party's history of issue attention and traditional ties with certain social groups. Such constituency-based, or associative,

\footnotetext{
${ }^{2}$ Admittedly, this distinction may be less relevant in the US two-party system. In Western Europe, even small and unpopular parties can be seen as the associative issue owner due to strong issue politicization. For such small parties, gaining competence issue ownership is more difficult. Cases in point are Green or radical-right wing parties, which often enjoy associative issue ownership of the environment and immigration issues, respectively.

${ }^{3}$ The survey question he used asked respondents: "Which political party, the Democrats or the Republicans, do you trust to do a better job handling each of the following issues?" Variations of this question have been used in most subsequent work on issue ownership (for a review, see Walgrave et al., 2015).
} 
issue ownership should be quite resilient in the short run. Therefore, we derive our first expectation:

H1: Individual perceptions of associative issue ownership are more stable than individual perceptions of competence issue ownership.

This discussion questions what drives stability and change. Researchers have only recently started to investigate the sources of issue ownership stability and change. In line with the idea of performance-based ownership, issue ownership perceptions have been shown to change in response to real-world developments, such as in the economy and national security, which voters link to the incumbent government's performance (Bélanger, 2003; Stubager and Slothuus, 2013). Without accounting for real-world indicators, other studies have confirmed that participation in government affects voters' issue ownership perceptions (de Bruycker and Walgrave, 2014; Walgrave and Lefevere, 2017). Another factor is party system change: the emergence of new parties challenges the issue ownership perceptions of established parties (Bélanger, 2003). However, most research has focused on the role of campaign information-either on the effect of parties' own campaign material (e.g., Walgrave and de Swert, 2007; Dahlberg and Martinsson, 2015) or of their statements in the mass media (e.g., Aalberg and Jenssen, 2007; Kleinnjenhuis and Walter, 2014; Tresch et al., 2015; Walgrave et al., 2009; Walgrave and Lefevere, 2017).

In this study, we concentrate on the (conditional) role of the election campaign's media coverage. In our view, media campaign coverage is an important driver of voters' issue ownership assessments. Government performance, party system change, or direct party communications may not automatically affect voters' issue ownership perceptions. While voters may directly feel the impact of high inflation rates, they may never personally experience the rise of unemployment or crime rates. When 
considering such issues, voters may not know about the incumbent government's poor performance- unless they hear about it from their discussion networks or from the media. Likewise, new parties must actively "occupy" issues upon which they want to be perceived as more committed and competent than their opponents. They can do so in their manifestos or other campaign material; however, it is mainly through the mass media that they reach the general public (Esser and Strömbäck, 2014). Mainstream media attention is crucial in reaching a wide public audience, particularly in countries such as Switzerland, where parties' campaign budgets are limited. In this study, we not only test the idea that media campaign coverage affects voters' issue ownership perceptions, as previous literature has done, but also that the effect of media coverage is conditional on issue salience and, importantly, that its strength varies for voters' perceptions of associative and competence issue ownership.

The general view in the literature is that issue ownership perceptions act as filters for assimilating specific campaign messages (Ansolabehere and Iyengar, 1994). Due to a "confirmatory bias" that makes voters more willing to accept news that support their existing stereotypes (Holian, 2004: 98), messages from the issue owner are incorporated, whereas other parties' messages are rejected. In other words, voters are expected to stick to their issue ownership evaluations when they receive campaign messages from the issue-owning party. By extension, the same mechanism should apply to media coverage: when a party that a voter considers as the issue owner is highly visible in issue-specific media campaign coverage, this voter should be likely to stick to the initial issue ownership assessment. This informs our second hypothesis:

$\mathrm{H} 2$ : The higher the share of issue-specific media campaign coverage of a party that a voter considers as issue owner, the higher the likelihood that this voter maintains her/his issue ownership perceptions. 
Going one step further, we argue that this stabilizing effect of media coverage on voters' issue ownership perceptions is conditional on issue salience. Issue salience is central to issue ownership theory: it is seen as the "critical difference among elections" (Petrocik, 1996: 826). Campaigns increase the salience of some issues and, in doing so, affect the criteria (i.e., issues) by which voters judge parties: citizens whose individual problem concerns are primed in a campaign will cast their ballot for the issue-owning party. Several empirical studies have shown that voters' perceptions of parties' (competence) issue ownership only affect their vote choice for issues that are important for them (Bélanger and Meguid, 2008; Green and Hobolt, 2008). Thus, issue salience matters for issue ownership voting. In a similar way, issue salience can also be expected to condition the impact of media coverage on voters' issue ownership perceptions. People's beliefs about important issues are less likely to change in response to media coverage than their opinions about less important issues (e.g., Lecheler et al., 2008). In other words, the postulated stabilizing effect of media coverage on voters' issue ownership perceptions should be stronger for issues that are important for a voter than for non-salient issues. Hence, our third hypothesis reads as follows:

H3: The stabilizing effect of media coverage on voters' issue ownership perceptions is stronger for salient than for non-salient issues.

Finally, and most importantly, having the opportunity to analyze voters' perceptions of associative and competence ownership in a single study, we are interested in the differential role of media coverage on these two dimensions. Previous experimental work from Belgium suggests that being visible in media coverage does not have the same effect on perceptions of associative and competence issue ownership. Focusing on the associative dimension, Tresch et al. (2015) tested the effect of "issue 
retention"- when a party makes a statement on an owned issue in the media - and of "issue trespassing" - when a party makes a statement on an issue that is owned by another party — on voters' issue ownership perceptions. The researchers found that parties can increase their reputational advantage over their competitors by campaigning on an owned issue; however, parties did not gain from addressing issues associated with another party. This suggests that campaign coverage of an issueowning party (a situation similar to issue retention) should have the predicted stabilizing effect on a voter's probability to maintain his/her perception of associative issue ownership, at least for salient issues. The reason is that this media coverage confirms and reinforces the voter's stereotypes about the party. By contrast, issuespecific campaign coverage of a party that the voter does not recognize as an associative issue owner (a situation similar to issue trespassing) is rejected because it runs counter to the voter's expectations about the party. This latter mechanismrejecting information that runs counter to existing stereotypes - is likely to be weaker in the case of competence issue ownership. Because voters' perceptions of competence ownership are more variable and context-dependent, they should more strongly respond to media campaign coverage, at least for salient issues. Indeed, another Belgian experimental study (Walgrave et al., 2009) suggested that issue trespassing does affect voters' evaluations of competence ownership. When a party makes a statement on an issue for which it is generally not seen as most competent, it can significantly increase its issue-handling reputation - at least if the issue owner does not simultaneously make a statement about this issue in the media. Thus, it is necessary for parties to campaign on owned issues to maintain their competence reputation and to neutralize other parties' messages (see also Dahlberg and Martinsson, 2015). This suggests that for salient issues, issue-specific campaign coverage of a party that a voter considers as the issue owner is likely to have a stronger stabilizing effect on the voter's 
assessment of competence issue ownership than on the voter's perception of associative issue ownership. Thus, our last hypothesis is:

H4: Media coverage of salient issues has a stronger stabilizing effect for voters' assessment of competence ownership than for their perception of associative issue ownership.

\section{Methods}

\section{Data and Measures}

Our analysis is based on a new dataset that links voter survey data with media content data that were both collected as part of the 2015 Swiss National Election Study (Selects). To assess how and why a voter's issue ownership perception varies during an election campaign, we resort to a combined, four-wave panel/rolling cross-section online survey (Selects, 2016). We use data from the first two panel waves. ${ }^{4}$ The initial random sample was drawn from the official population register and included 29,500 Swiss citizens. Among this sample, 11,073 individuals participated in the first precampaign wave between mid-June and late July. The second panel wave took place during the campaign and took the form of a rolling cross-section survey, with approximately 120 interviews conducted per day during the 62 days prior to Election Day $(\mathrm{N}=7,399) .{ }^{5}$ For five issues (migration, European integration, the economy, social policy, and the environment), respondents were asked to name the party they considered "most competent in handling the issue" (competence issue ownership) and

\footnotetext{
${ }^{4}$ We do not take into account wave 4, which also includes a series of questions about respondents' perceptions of associative and competence issue ownership, because it was organized almost two months after the election starting on December 9, while we only have campaign information until Election Day (October 19). In addition, there is a risk that voters updated and rationalized their issue ownership assessments in light of the election results.

${ }^{5}$ Using the AAPOR response rate calculator, AAPOR Response Rate 1 amounts to 38 percent in wave 1 , and to 75 percent in wave 2 .
} 
the party that "cares most about the issue" (associative issue ownership). For each issue, respondents could identify only one party as the associative and competence issue owners, respectively, or answer with "Don't know" (there was no option to name several parties or to say that no party is competent/cares most about the issue). Unsurprisingly, most voters mentioned the five largest parties as the issue owners. These were the traditional governing parties - the Liberals (FDP), ChristianDemocrats (CVP), Social-Democrats (SP), and Swiss People's Party (SVP) - and the Green Party (GP). We stacked the dataset to obtain one row of observation per issue for each respondent $(\mathrm{N}=36,995$; i.e., 7,399 respondents in the second wave times five issues). Our two dependent variables measure the stability of competence and associative issue ownership perceptions, respectively: respondents who indicated the same party as the issue owner in both panel waves were coded 1, whereas respondents who changed their initial issue ownership perceptions during the campaign were coded 0 . The latter category includes respondents who switched between different parties, as well as those who switched between "Don't know" and a party. Note that cases with missing values in one or both of the waves, as well as cases in which respondents answered "Don't know" in both waves, were excluded from our analyses. ${ }^{6}$ This left us with $\mathrm{N}=31,679$ cases $(6,711$ respondents) for associative issue ownership evaluations and $\mathrm{N}=27,944$ cases $(6,206$ respondents $)$ for competence issue ownership assessments.

To evaluate the impact of campaign coverage on a voter's perception of associative and competence issue ownership, we combine this survey data with data from the Selects media analysis (Selects, 2017). The media analysis was conducted on all politics-related articles published during the election campaign (August 1 until

\footnotetext{
${ }^{6}$ A respondent who answers "Don't know" in both waves cannot be regarded as having a stable perception of issue ownership. In that sense, these answers are not equal to naming the same party in both waves.
} 
October 18) in 92 different media outlets $(\mathrm{N}=45,863) .{ }^{7}$ These media outlets range from different print newspapers and magazines (tabloids, quality newspapers, local newspapers, Sunday papers) to online news portals (e.g., Swissinfo) or the website of the national public broadcaster (srf.ch). For every article, the dataset provides the estimated probabilities that this article deals with a certain topic. Topics were identified inductively using the structural topic model (STM). ${ }^{8}$ We started by assigning every article to the topic with the highest probability, and then we recoded the topics into the voter survey's five issues (migration $\mathrm{N}=3,316$; economy $\mathrm{N}=2,782$; European integration $\mathrm{N}=2,665$; environment $\mathrm{N}=2,262$; social policy $\mathrm{N}=2,789$; plus a residual category for topics that did not match any of the five issues). The media data further provided information about political actors mentioned in the news articles. For each article, a keyword search was used to code the presence of any of the nearly 4,000 individual candidates and parties running for election. In the articles attributed to the five issues of the voter survey, we found a total of 27,214 party mentions (migration $\mathrm{N}=8,731$; economy $\mathrm{N}=3,917$; European integration $\mathrm{N}=2,866$; environment $\mathrm{N}=$ 2,913; social policy $\mathrm{N}=8,000$ ). Figure A1 in the Appendix shows the share of party mentions in media coverage across the five issues.

\footnotetext{
${ }^{7}$ Based on human-coded training data, supervised classification was used to identify relevant news articles dealing with Swiss politics. Overall, the final ensemble classifiers performed satisfactorily. The combined model performance metric, $F 1$ score, was 0.93 for German language documents and 0.91 for French language documents. After the ensemble classifications were conducted, 100 positively classified documents for German and 50 for French were randomly sampled and manually checked. The precision of the actual results of the ensembles was 0.90 for German and 0.92 for French. For a detailed description and evaluation of the classification, see Wüest et al. (2016: 9-12).

${ }^{8}$ The structural topic model (STM) estimates document probabilities for latent semantic variables, called topics. Belonging to the group of mixed-membership models, the STM assumes that each document consists of a mixture of topics. A crucial aspect of the STM pertains to its granularity, which is the number of topics. For selecting the number of topics, the topics' semantic coherence (the consistency of probable words within a topic) and their discrimination (how well the words within a topic are separated from words within other topics) were evaluated using word2vec word embeddings, which suggested a granularity of 18 for French and 17 for German for a range of three to 20 topics. Based on the 30 most probable words for each topic, human coders identified the substance of the different topics and assigned labels to them. In addition, the human coders read some high probable documents for each topic to validate the substantive labelling of topics. The most probable words for the five issues are available upon request in French and German, as well as entire documents with high probabilities for each topic. For more information about the coding procedure, see Wüest et al. (2016: 13-4).
} 
We then matched the media and survey data following the general procedure for linkage studies described by de Vreese et al. (2017). We linked the media data to the survey data based on which party respondents mentioned as the competence and associative issue owners, respectively, in wave 1 of the combined panel/RCS survey, as well as two questions in wave 2 that asked respondents "Which (printed) newspaper did you read the most in the last days?" and "Which online news site or online newspaper did you visit the most in the last days?". It was impossible to match either a print or an online media outlet for $\mathrm{N}=1,803$ respondents. Whenever matching was possible, we only considered news articles that were published before the day of the interview in wave 2. Hence, we do not assume that everyone had been exposed to the same amount of campaign coverage; we only account for information that an attentive respondent could potentially have encountered in his/her most read print and/or online media outlet before answering our questionnaire. Due to the RCS design, the interviews in the second wave were spread over a long period of time; some respondents were contacted two weeks after the campaign started, whereas others were interviewed a few days before the election. Each respondent was assigned the cumulated media share ${ }^{9}$ of the party he/she considered to be the issue owner in wave 1 for each of the five issues up to the day before the second interview. Note that we only had information about the amount of a party's issue-specific media coverage but not about this coverage's qualitative nature (tone).

To test the expected conditional effect of media coverage, we interacted our media coverage variable with issue salience, a binary variable based on a survey question that asked respondents to assess the importance of each of the five issues. We further included several control variables that are known to affect voters' issue ownership

\footnotetext{
${ }^{9}$ We took the average between the cumulated share in the print and online media if both could be matched to a respondent. The variable ranges from 0 for a share of 0 percent to 1 for a 100 percent share of a party's issue-specific media coverage relative to all other parties.
} 
perceptions. The first and most important one is voters' party identification. The role of partisanship in voters' competence issue ownership evaluations is well documented: voters who identify with a party are more likely to consider this party as the competence issue owner (Stubager and Slothuus, 2013; Therriault, 2015). For our analyses, the important information is not so much with which specific party a respondent identifies but rather whether the respondent feels close to the party that he/she identifies at the start of the campaign as the issue owner for each of the five issues. Hence, our variable takes a value of 1 for respondents who feel close to the party they consider the issue owner in panel wave 1 and a value of 0 for respondents who feel closer to another party than the party they name as the issue owner or who do not feel close to any party. Second, we controlled for a voter's level of political knowledge, and the variable ranges from 0 to 1 and is assessed based on six factual questions on the Swiss government. More knowledgeable voters are more likely to be exposed to the campaign and to learn from it (e.g., Kleinnijenhuis and Walter, 2014). At the same time, they are more likely to reject campaign messages that are inconsistent with their predispositions (Zaller, 1992). Hence, more knowledgeable voters are more likely to stick to their pre-campaign issue ownership perceptions. Third, we expected the same mechanism to be true for a voter's interest in politics, which is measured by a binary variable. Fourth, we controlled for a voter's attention to the campaign (binary variable), as well as the time between pre-campaign and campaign interviews. We expected these two variables to exert a similar, and negative, effect on a voter's likelihood to maintain his/her perceptions of competence and associative issue ownership. Indeed, previous research has shown that voters who are exposed longer to campaign information are more likely to update their existing issue ownership perceptions (Kleinnijenhuis and Walter, 2014; Walgrave and Lefevere, 2017). Fifth, we expected that a voter is more likely to keep his/her issue ownership 
assessment if the party he/she considers the issue owner also enjoys ownership in the eyes of the general public. Kleinnijenhuis and Walter (2014) referred to this mechanism as "contagion effect," which is the idea that a voter can be expected to know that the general public perceives left-wing parties to be the owner of social policy issues, such as old age pension or unemployment insurance, or that Green parties are generally associated with environmental issues - even if a voter's own perceptions diverge from these aggregate-level reputations. This is the case because parties with aggregate-level issue ownership tend to get more issue-specific news attention than other parties (e.g., Petrocik, 1996; Petrocik et al., 2003; van Camp, 2017). Hence, a voter has more opportunities to learn from the media about party-issue connections of parties that have ownership on the aggregate level, thus creating a stronger likelihood of maintaining perceptions if the existing issue ownership evaluations align with the general public's issue ownership assessment. Therefore, we added a variable of 1 for a voter who considers a party with aggregate-level ownership as the issue owner and a value of 0 for a voter whose perceptions diverge from the general public. ${ }^{10}$ Sixth, we controlled for party size, based on the party's electoral share in the previous national election, ${ }^{11}$ because larger parties generally have higher news value and tend to get more media attention than smaller parties (e.g., van Camp, 2017). Therefore, it could be that voters' issue ownership perceptions are more stable for large parties than for small parties. Finally, we added several socio-demographic control variables. Gender is a binary variable coded 0 for females and 1 for male respondents; age is measured

\footnotetext{
${ }^{10}$ See Figures A2a and A2b in the Appendix for the distribution of aggregate issue ownership. Our results show issue ownership of the Social Democrats on social policy, the Liberals on the economy, the Greens on the environment, and the Swiss People's Party on immigration. It is more difficult to attribute aggregate ownership of the European integration issue to a specific party.

${ }^{11}$ Federal Statistical Office (2018). Party strengths 2011. Retrieved from https://www.bfs.admin.ch/bfs/fr/home/statistiques/politique/elections/conseil-national/forcepartis.html\#-264904466.
} 
in years, and education is measured on a 13-point scale. Note that all control variables were assessed in the first pre-campaign wave. Due to item non-response on these control variables, we ended up with $\mathrm{N}=16,102$ cases $(4,370$ respondents) for competence issue ownership and with $\mathrm{N}=20,842$ cases $(4,934$ respondents) for associative issue ownership. Table A1 in the Appendix reports the descriptive statistics for all variables.

\section{Model}

In our stacked dataset, each respondent appears several times: once for each of the five issues for which he or she identified an issue-owning party. Thus, observations pertain to issue-party combinations and are nested in respondents. These respondents belong to two non-nested contexts: parties and issues. Due to this complex data structure, we ran logistic, cross-classified random intercept models to analyze the stability of voters' perceptions of competence and associative issue ownership between the two panel waves. We estimated the following model:

$$
\begin{aligned}
\operatorname{logit}\left(P_{i j z 1 z 2}\right) & =\beta_{0}+\beta_{1} \text { Media }_{i j z 1 z 2}+\beta_{2} \text { Sal }_{i j z 2}+\beta_{3} \text { Media }_{i j z 1 z 2} \times S_{i j z 2} \\
& +\beta_{4} \text { AggIO }{ }_{i z 1 z 2}+\beta_{5} \text { Pid }_{i j z 1}+\beta_{6} \text { Psize }_{i z 1}+\sum_{k} \beta_{k} x_{k(i j)}+u_{0 j} \\
& +u_{0 z 1}+u_{0 z 2}+e_{i(j z 1 z 2)}
\end{aligned}
$$

Where the logit of $\mathrm{P}_{\mathrm{ijz} 1 \mathrm{z} 2}$ represents the probability that a voter (denoted $j$ ) will maintain his/her issue ownership perception of a given party (denoted $z_{l}$ ) on a specific issue (denoted $z_{2}$ ). The main variables of interest are Media, the share of issue-specific media attention for the party a voter considers the (competence or associative) issue owner in panel wave 1; Sal, the salience that a citizen grants to each of the five issues; and Media x Sal, the interaction term. AggIO refers to the issue-owning party on the aggregate level for the general public, Pid is party identification, Psize is party size, 
and $x_{k}$ refers to a series of respondent-specific control variables (political knowledge, political interest, campaign attention, sex, age, education, days between panel waves). The random effects parameters $\left(\mathrm{u}_{0 \mathrm{j}}, \mathrm{u}_{0 \mathrm{z} 1}, \mathrm{u}_{0 \mathrm{z} 2}\right)$ are assumed to be independent of each other and normally distributed (with a mean of 0 and a variance of $\sigma_{u 0}^{2}$ ).

\section{Results}

(In) stability of individual issue ownership perceptions

Our first aim was descriptive: we simply assessed the stability and change of voters' issue ownership perceptions during a real-world election campaign. Thus, we tested the expectation that voters' perceptions of associative issue ownership are more stable than their evaluation of parties' issue-handling competences. Figure 1 lends support to this hypothesis (H1): on average, over all issues, nearly half the respondents (49.2\%) updated their perceptions of competence issue ownership between the two panel waves; however, only 37.5 percent changed their assessment of party-issue associations.

\section{--- FIGURE 1 ABOUT HERE---}

This proportion may seem high, and one might wonder if issue ownership truly exists in Switzerland. Yet, high aggregate-level stability often goes hand in hand with high individual-level variability (e.g., Kleinnijenhuis and Walter, 2014; Lanz and Sciarini, 2016). Furthermore, the level of instability reported in Figure 1 is much lower than the numbers from a long-term panel study by Walgrave and Lefevere (2017), who found that 57 percent of all respondents changed their associative issue ownership perception between the 2014 and 2009 Belgian elections. 
The greater stability of voters' associative rather than competence issue ownership perception can be observed across all issues but one. The only exception is European integration: on this issue, voters' perceptions of associative ownership are slightly more variable than their competence evaluations. Several peculiarities of the European integration issue in Switzerland may explain this pattern. First, the integration issue's salience dramatically increased in the 2015 election as compared to previous elections (Lutz, 2016: 26), presumably as a consequence of a popular vote against mass immigration in February 2014, which complicated the bilateral relationships between Switzerland and the European Union. Second, among the five issues, the European integration issue is the only one lacking a clear associative issue owner at the aggregate level (Figures A2a and A2b in the Appendix). Third, as compared to the previous national election in 2011, the aggregate-level competence issue owner changed (from the Swiss People's Party to the Liberals). On the other four issues, we found highly similar patterns across election years. Contrasting with the findings from a long-term panel study in Belgium (Walgrave and Lefevere, 2017), we found limited cross-issue variation in the stability of voters' issue ownership perceptions in Switzerland.

\section{Determinants of (un)stable issue ownership perceptions}

We assessed the (conditional) role of media campaign coverage on the (in)stability of individual voters' associative and competence ownership perceptions (H2 and H3) and tested the expectation that media campaign coverage has a differential impact on a voter's assessment of the two issue ownership dimensions (H4). Table A2 in the Appendix presents the estimates and odds ratios for two cross-classified random 
intercept models, predicting the stability of voters' competence and associative issue ownership. $^{12}$

The findings run counter to our second hypothesis (H2): media coverage of party-issue statements does not directly affect the stability of a voter's issue ownership perceptions - neither in the competence nor in the associative issue ownership models. However, and importantly, we discovered a positive and statistically significant interaction effect with issue salience in both models. For a better understanding of these effects, Figures $2 \mathrm{a}$ and $2 \mathrm{~b}$ below show the average marginal effects for all variables in our model. Continuous variables are set to their mean, while discrete variables are set to their mode (see Table A1 in the Appendix for a summary of the independent variables). If the confidence interval does not include the value zero, the average marginal effect is significant at the $p=0.05$ level.

\section{--- FIGURES 2A AND 2B ABOUT HERE---}

The figures lend support to the idea that the impact of media coverage on a voter's probability to hold stable issue ownership perceptions is conditioned by issue salience. For non-salient issues, the average marginal effect is insignificant; thus, media coverage has no effect on a voter's probability to maintain his or her issue ownership perception. For salient issues, the average marginal effect is positive and significant for both competence and associative issue ownership. This lends support to hypothesis 3: when the median voter perceives party $\mathrm{X}$ to own an issue of importance to him/her before the start of the campaign (panel wave 1), his/her chances of still considering party $\mathrm{X}$ to be the owner of this issue in the second interview increases with growing

\footnotetext{
${ }^{12}$ Note that most of the variance is between respondents in both models; however, the variance on the party level is also quite sizeable in the associative ownership model.
} 
levels of media campaign coverage. In other words, issue-specific media campaign coverage of a given party identified as the issue owner by a voter has the expected stabilizing effect but only for issues that are salient for this voter. This finding applies to both competence and associative issue ownership perceptions. However, and in line with hypothesis 4 , the stabilizing effect of media coverage on a voter's likelihood to maintain his/her perception of ownership of a salient issue is stronger for the competence than the associative dimension. In fact, the average marginal effect for a one-unit increase of a party's share of issue-specific media coverage (i.e., from 0 to 100 percent) amounts to 0.79 for competence issue ownership and to 0.34 for associative issue ownership.

Regarding our control variables, party identification and aggregate issue ownership are very strong predictors of issue ownership stability—stronger than media coverage. The probability of stable issue ownership perceptions greatly increases for a voter who identifies with party $\mathrm{X}$, as compared to an otherwise similar voter who does not feel close to party X. This holds true for both models, even though the partisanship effect is much stronger in the competence ownership model. Furthermore, the results point toward a rather strong "contagion effect" (Kleinnijenhuis and Walter, 2014). Voters seem to maintain their perception of issue ownership more easily if it aligns with the general public's issue ownership assessment. As expected, this effect is stronger for perceptions of associative ownership than for competence evaluations. Among the other control variables, only political knowledge and political interest have positive and sizeable effects in both models.

\section{Robustness checks}

While linking media content and panel survey data is a state-of-the art approach to identifying media effects on individuals' attitudes, there is no single way of measuring 
media exposure and combining it with survey data (de Vreese et al., 2017). We tested two alternative specifications of our media coverage variable to assess the robustness of our findings. First, we analyzed whether the strength of the media effect depends on the recency by which party-issue statements are encountered in the media. To test the idea that more recent information is better remembered and more accessible when forming a judgment, news items published in the two weeks before the interview in the second panel wave were given a double weight. In a second test, we weighted the media coverage variable by an individual's general news attention to test the idea that party-issue linkages in the media have a stronger impact on individual issue ownership perceptions when a voter is more attentive to the news. ${ }^{13}$ Table A4 in the Appendix shows our conclusions were confirmed by these robustness checks (average marginal effects plots available upon request).

Overall, we can be confident that media campaign coverage, in interaction with issue salience, matters for the stability of a voter's perception of parties' issue ownership, particularly for the competence dimension. However, these media effects are rather weak. One explanation might be a measurement error in content analysis and selfreported media use, which usually leads to finding minimal media effects in linkage studies (Scharkow and Bachl, 2017). Another explanation is that our self-reported media use variable allows for only a conservative test of media effects because it simply accounts for citizens' most used print or online media.

\footnotetext{
${ }^{13}$ It is more common for linkage studies to weigh media content features with a self-reported media exposure variable, which is typically measured as the number of days a respondent reports to use a given news outlet (de Vreese et al., 2017). Given that the Selects panel survey did not include such a measure, we turned to a general news attention measure. The question's wording was as follows: "How attentive were you to political news in the following media in the past few days?" Answers were measured on a four-point scale ranging from "very attentive" to "not at all attentive." We used answers for news in print media (paid and unpaid) and online news sites, depending on which media outlet the respondent reported to have used most in the previous days.
} 


\section{Discussion and Conclusion}

Recent scholarship suggests that issue ownership is not only variable over time but two-dimensional, with an associative and a competence dimension. Our study is the first to directly compare the stability and change of both issue ownership dimensions and to predict the differential and conditional impact of media campaign coverage on the stability of a voter's ownership perceptions during an election campaign, taking the example of the 2015 national elections in Switzerland.

We found that individual competence ownership is less stable than perceptions of party-issue associations. More respondents updated their perception of competence ownership than of associative ownership between the panel survey's two waves. Thus, our results confirm the previously untested but widely held assumption that associations are more stable than competence attributions. Furthermore, a party's issue-specific visibility in media campaign coverage has a stronger impact on competence than on associative issue ownership. When a party, which is seen to be the (competence or associative) owner of a specific issue by a voter, is strongly present in the media's issue-specific campaign coverage, chances increase that the voter will maintain his/her issue ownership evaluation—but this effect only shows for salient issues.

From a normative perspective, the stability of voters' perceptions of parties' ownership of salient issues in response to varying levels of issue-specific media coverage can be welcomed and is worth highlighting. To choose parties that best represent their preferences, voters must be able to connect issue-related considerations to the parties, for instance by assessing their commitment and competence to deal with issues of importance to them. While the media is often criticized for framing election campaigns as a strategic game while neglecting substantive issues and policy proposals (e.g., Aalberg et al., 2011), our findings show that issue-specific party campaign coverage 
in the media has the potential to shape voters' ratings of party competence and-to a lesser extent — their perceptions of parties' issue concerns.

Our results are obtained from a single case: Switzerland. The analysis of a real-world campaign in Switzerland confirms earlier results from experimental studies in other Western European countries that found issue ownership perceptions are rather unstable on the individual level and that media coverage is a driver of issue ownership stability and change. However, the observed differences between competence and associative issue ownership may be even more pronounced in other countries. For example, voters' perceptions of competence issue ownership may be more unstable in countries where government responsibility is clearer and where some parties can more easily be held accountable for poor performance than in the Swiss consensus system, where all major parties are represented in government and direct democracy further diffuses power. However, voters' perceptions of associative issue ownership may be more stable in countries with a less fragmented party system than the Swiss one, where many ideologically proximate parties are in a battle for issue ownership. While further testing is needed to assess the generalizability of our results, we believe our findings have important implications for future research in the fields of party competition and electoral behavior. Our results underline the usefulness of the conceptual distinction between associative and competence issue ownership. While our study is the first to jointly assess the (in)stability of both dimensions of issue ownership in a nonexperimental study, it is only the first step in the direction of disentangling the concept of issue ownership, as well as to establish its determinants and effects. Previous work has shown that voters' perceptions of associative and competence issue ownership both influence their vote choice — albeit in different ways (e.g., Lachat, 2014; Lutz and Sciarini, 2016). The precise mechanisms still need to be explored, and one important question is to determine how voters with conflicting views on the two dimensions of 
issue ownership make their electoral choice. Previous studies also suggest that voters who update their competence issue ownership perceptions during a campaign are more likely to change their vote intention (Lanz and Sciarini, 2016). Thus, for parties, it is essential to maintain their issue-handling reputations on issues of importance to voters - and our findings suggest that being visible in the media may help them do so. Furthermore, media visibility has been shown to increase vote intentions for the issueowning party (Thesen et al., 2017). Therefore, further research is needed to examine the full causal link between campaign information, individual competence, and associative issue ownership perceptions and the final vote choice.

\section{References}

Aalberg, Toril, Jesper Strömbäck, and Claes H. de Vreese. 2011. The framing of politics as strategy and game: A review of concepts, operationalizations and key findings. Journalism 13(2): 162-178.

Aalberg, Toril, and Anders T. Jenssen. 2007. Do Television Debates in Multiparty Systems Affect Viewers? A Quasi-Experimental Study with First-Time Voters. Scandinavian Political Studies 30:115-35.

Ansolabehere, Stephen, and Shanto Iyengar. 1994. Riding the Wave and Claiming Ownership Over Issues. Public Opinion Quarterly 58: 335-357.

Bélanger, Eric and Bonnie M. Meguid. 2008. Issue salience, issue ownership, and issue-based vote choice. Electoral Studies 27 (3): 477-91.

Bélanger, Eric. 2003. Issue Ownership by Canadian Political Parties 1953-2001. Canadian Journal of Political Science 36 (3): 539-58.

Bellucci, Paolo. 2006. Tracing the cognitive and affective roots of "party competence": Italy and Britain, 2001. Electoral Studies 25: 548-69. 
Budge, Ian, and Dennis Farlie. 1983a. Party Competition - Selective Emphasis or Direct Confrontation? An Alternative View with Data. Pp. 267-305 in Western European Party Systems. Continuity and Change, edited by Hans Daalder and Peter Mair. Beverly Hills: Sage.

Budge, Ian, and Dennis Farlie. 1983b. Explaining and predicting elections. London: George Allen and Unwin.

Christensen, Love, Stefan Dahlberg, and Johan Martinsson. 2015. Changes and Fluctuations in Issue Ownership: The Case of Sweden, 1979-2010. Scandinavian Political Studies 38 (2): 137-57.

Dahlberg, Stefan, and Johan Martinsson. 2015. Changing Issue Ownership through Policy Communication. West European Politics 38 (4): 817-38.

Damore, David F. 2004. The Dynamics of Issue Ownership in Presidential Campaigns', Political Research Quarterly 57 (3): 391-7.

De Bruycker, Iskander, and Stefaan Walgrave. 2014. How a New Issue Becomes and Owned Issue. Media Coverage and the Financial Crisis in Belgium (2008-2009). International Journal of Public Opinion Research 26 (1): 86-97.

De Vreese, Claes H., Mark Boukes, Andres Schuck, Rens Vliegenthart, Linda Bos, and Yph Lelkes. 2017. Linking Survey and Media Content Data: Opportunities, Considerations, and Pitfalls. Communication Methods and Measures 11 (4): 22144.

Dolezal, Martin, Laurenz Ennser-Jedenastik, Wolfgang C. Müller, and Anna Katharina Winkler. 2014. How parties compete for votes: A test of saliency theory. European Journal of Political Research 53 (1): 57-76.

Egan, Patrick J. 2008. Issue Ownership and Representation: A Theory of Legislative Responsiveness to Constituency Opinion, available at SSRN: http://ssrn.com/abstract=1239464. 
Esser, Frank, and Jesper Stömbäck. 2014. Mediatization of Politics. Understanding the Transformation of Western Democracies. London: Palgrave Macmillan.

Green, Jane, and Sara B. Hobolt. 2008. Owning the issue agenda: Party strategies and vote choices in British elections. Electoral Studies 27 (3): 460-76.

Hayes, Danny. 2008. Party Reputations, Journalistic Expectations: How Issue Ownership Influences Election News. Political Communication 25 (4): 377-400.

Holian, David B. 2004. He's Stealing My Issues! Clinton's Crime Rhetoric and the Dynamics of Issue Ownership. Political Behavior 26 (2): 95-124.

Kleinnijenhuis, Jan, and Annemarie Walter. 2014. News, Discussion, and Associative Issue Ownership: Instability at the Micro Level Versus Stability at the Macro Level. The International Journal of Press/Politics 19 (2): 226-45.

Lachat, Romain. 2014. Issue ownership and the vote: The Effects of Associative and Competence Ownership on Issue Voting. Swiss Political Science Review 20 (4): $727-40$.

Lanz, Simon, and Pascal Sciarini. 2016. The short-time dynamics of issue ownership and its impact on the vote. Journal of Elections, Public Opinion and Parties, 26 (2): $212-31$

Lecheler, Sophie, Claes H. de Vreese, and Rune Slothuus. 2009. Issue importance as a moderator of framing effects. Communication Research 36 (3): 400-25.

Lutz, Georg (2016). Eidgenössische Wahlen 2015. Wahlteilnahme und Wahlentscheid. Lausanne: FORS.

Lutz, Georg, and Pascal, Sciarini. 2016. Issue Competence and its Influence on Voting Behavior in the Swiss 2015 Election. Swiss Political Science Review 22 (1): 5-14.

Petrocik, John R. 1996. Issue ownership and presidential elections, with a 1980 case study. American Journal of Political Science 40 (3): 825-50. 
Petrocik, John R., William L. Benoit, and Glenn J. Hansen. 2003. Issue Ownership and Presidential Campaigning, 1952-2000. Political Science Quarterly 118 (4): $599-626$.

Scharkow, Michael, and Marko Bachl. 2017. How Measurement Error in Content Analysis and Self-Reported Media Use Leads to Minimal Media Effect Findings in Linkage Analyses: A Simulation Study. Political Communication 34(3): 323-343.

Seeberg, Henrik. 2017. How Stable Is Political Parties' Issue Ownership? A CrossTime, Cross-National Analysis. Political Studies 65(2): 475-492.

Selects (2017). Media analysis 2015 [Dataset]. Distributed by FORS, Lausanne, $\underline{\text { www.selects.ch }}$

Selects (2016). Panel/Rolling-cross-section study 2015 [Dataset]. Distributed by FORS, Lausanne, www.selects.ch

Sides, John. 2006. The Origins of Campaign Agendas. British Journal of Political Science 36 (3): 407-36.

Stubager, Rune, and Rune Slothuus. 2013. What Are the Sources of Political Parties' Issue Ownership? Testing Four Explanations at the Individual Level. Political Behavior 35 (3): 567-88.

Thesen, Gunnar, Christoffer Green-Pedersen, and Peter B. Mortensen. 2017. Priming, Issue Ownership, and Party Support: The Electoral Gains of an Issue-Friendly Media Agenda. Political Communication 34(2): 282-301.

Therriault, Andrew. 2015. Whose Issue Is It Anyway? A New Look at the Meaning and Measurement of Issue Ownership. British Journal of Political Science 45 (4): 929-38.

Tresch, Anke, Jonas Lefevere, and Stefaan Walgrave. 2015. "Steal me if you can!" The impact of campaign messages on associative issue ownership. Party Politics 21 (2): 198-208. 
Van Camp, Kirsten. 2017. Issue ownership as a determinant of political parties' media coverage. Communications - The European Journal of Communication Research.

Van der Brug, Wouter. 2004. Issue Ownership and Party Choice. Electoral Studies 23: 209-233.

Walgrave, Stefaan, Jonas Lefevere, and Michiel Nuytemans. 2009. Issue Ownership Stability and Change: How Political Parties Claim and Maintain Issues through Media Appearances. Political Communication 26 (2): 153-72.

Walgrave, Stefaan, Anke Tresch, and Jonas Lefevere. 2015. The Conceptualisation and Measurement of Issue Ownership. West European Politics 38 (4): 778-96.

Walgrave, Stefaan, Jonas Lefevere, and Anke Tresch. 2014. The Limits of Issue Ownership Dynamics: The Constraining Effect of Party Preference. Journal of Elections, Public Opinion and Parties 24 (1): 1-19.

Walgrave, Stefaan, Jonas Lefevere, and Anke Tresch. 2012. The Associative Dimension of Issue Ownership. Public Opinion Quarterly 76 (4): 771-82.

Walgrave, Stefaan, and Jonas Lefevere. 2017. Long-term associative issue ownership change: a panel study in Belgium. Journal of Elections, Public Opinion and Parties 27(4): 484-502.

Walgrave, Stefaan, and Knut de Swert. 2007. Where does issue ownership come from? From the party or from the media? Issue-party identifications in Belgium, 19912005. International Journal of Press/Politics 12 (1): 37-67.

Wüest, Bruno, Sarah Bütikofer, Adrian van der Lek, and Fionn Gantenbein. 2016. Selects Media Analyses 2015. Election Campaign in Swiss National Media. Codebook and Technical Report. Zürich: Department of Political Science.

Zaller, John. 1992. The Nature and Origins of Mass Opinion. Cambridge: Cambridge University Press. 
Figure 1: Stability of voters' perceptions of competence and associative issue ownership during the campaign, by issues

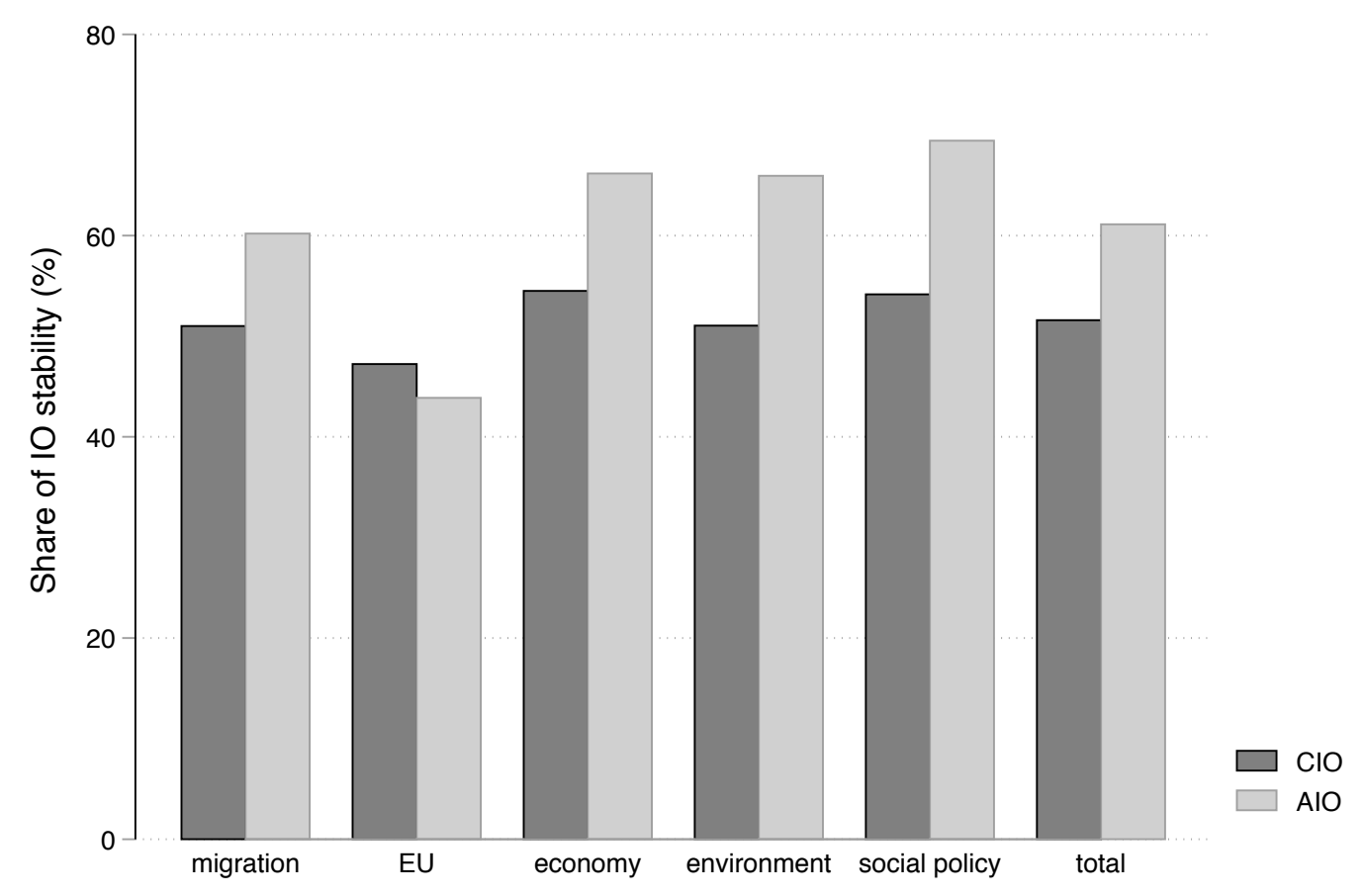


Figures 2a and 2b: Predicting individual issue ownership stability in the 2015 Swiss national election (Average Marginal Effects with 95\% CI)

Fig. 2a: Competence issue ownership

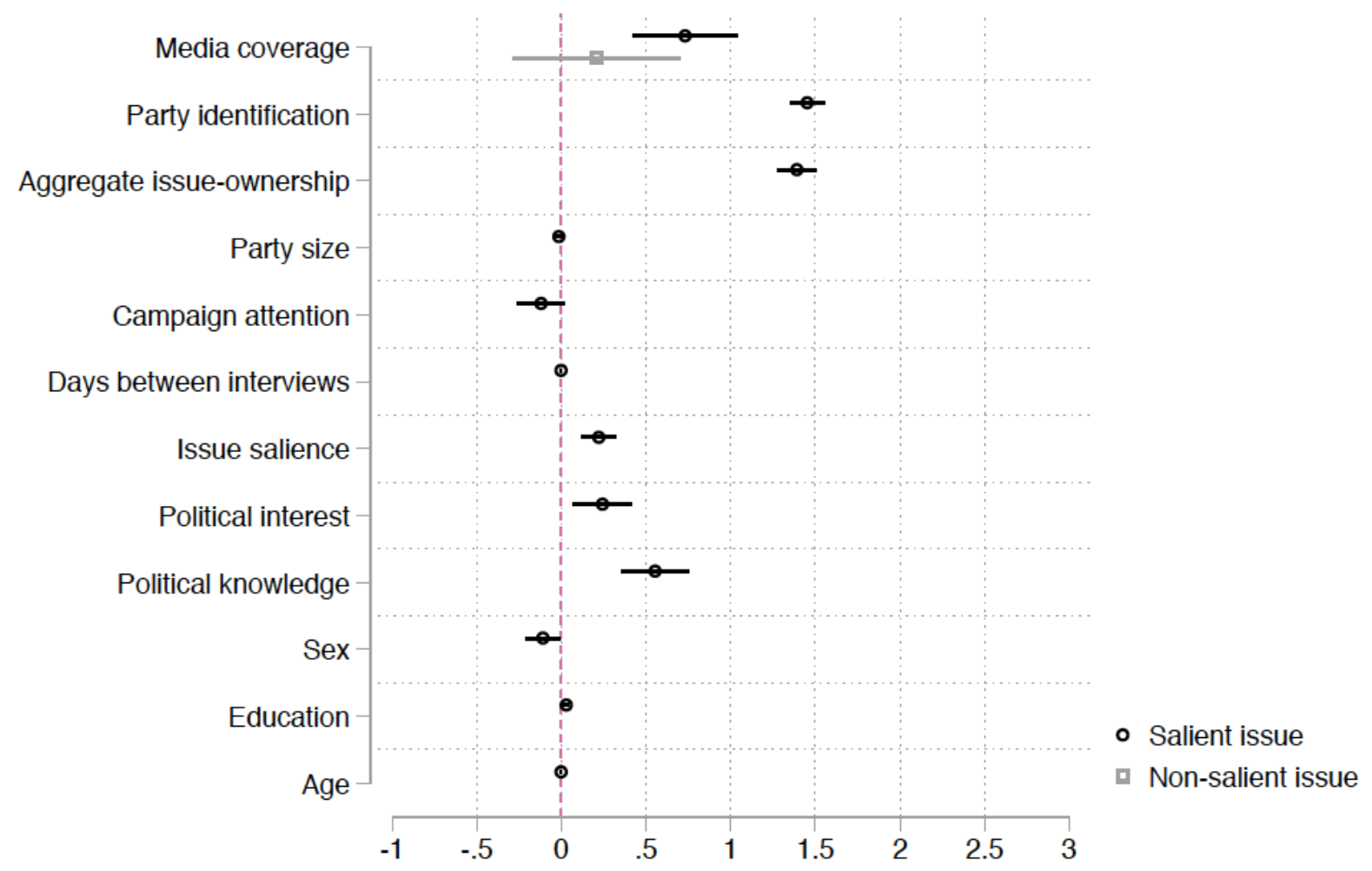

Fig. 2b: Associative issue ownership

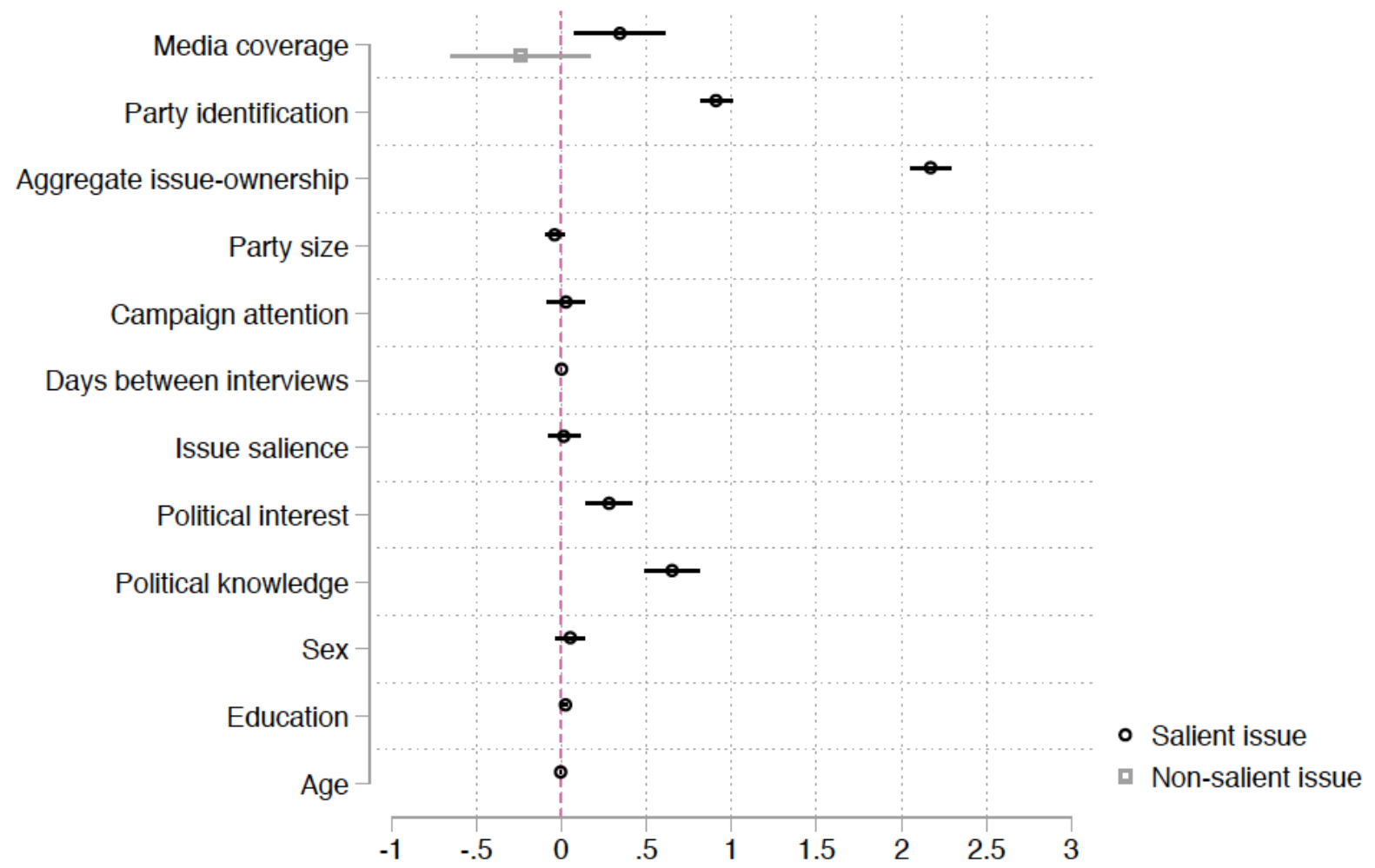

Note: All continuous predictors are at their means, all discrete predictors at their mode 